\title{
Cardiac rehabilitation via telerehabilitation in COVID-19 pandemic situation
}

\author{
Dian M. Sari ${ }^{1 *}$ (D) and Laurentia C. G. Wijaya ${ }^{2}$
}

\begin{abstract}
Background: Adherence to medication and lifestyle changes are very important in the secondary prevention of cardiovascular disease. One of the ways is by doing a cardiac rehabilitation program.

Main body of the abstract: Cardiac rehabilitation program is divided into three phases. The cardiac rehabilitation program's implementation, especially the second phase, center-based cardiac rehabilitation (CBCR), has many barriers not to participate optimally. Therefore, the third phase, known as home-based cardiac rehabilitation (HBCR), can become a substitute or addition to CBCR. On the other hand, this phase is also an essential part of the patients' functional capacity. During the coronavirus disease-2019 pandemic, HBCR has become the leading solution in the cardiac rehabilitation program's sustainability. Innovation is needed in its implementation, such as telerehabilitation. So, the cardiac rehabilitation program can be implemented by patients and monitored by health care providers continuously.
\end{abstract}

Short conclusion: Physicians play an essential role in motivating patients and encouraging their family members to commit to a sustainable CR program with telerehabilitation to facilitate its implementation.

Keywords: Cardiac rehabilitation, Coronavirus disease-2019 pandemic, Home-based exercise, Telerehabilitation

\section{Background: cardiac rehabilitation}

Cardiac rehabilitation (CR) is a comprehensive intervention for secondary prevention of cardiovascular disease (CVD) [1-3]. The 2016 European guidelines on CVD prevention in clinical practice emphasize that medication adherence and lifestyle changes are essential in secondary preventions of CVD, which can be increased and improved through CR programs; therefore, reducing the incidence of recurrent heart disease and the risk of death [2]. This program's ultimate goal is to prevent cardiacrelated disease recurrence, lower the risk of other cardiac events, such as arrhythmias or heart failure (HF), and improve patients' mental health status and quality of life cardiac-related diseases [3].

The cardiac rehabilitation program focuses on risk assessment and management [4]. This program

\footnotetext{
* Correspondence: sari.dianmarta@gmail.com

'Department of Physical Medicine and Rehabilitation, Faculty of Medicine, Universitas Padjadjaran, Bandung, Indonesia

Full list of author information is available at the end of the article
}

implements a preventive lifestyle to control risk factors of cardiac diseases, such as obesity, hypertension, diabetes, and dyslipidemia. Cardiac rehabilitation includes medical evaluation; physical exercise, controlling nutritional intake, lipid levels, and blood pressure (BP); planning programs to reduce cigarette smoking and alcohol consumption; stress management; modified individualized lifestyle consultation; tailored targeted pharmacological therapy; patient education; and psychological counseling $[1,3]$. The CR program components are aerobic training, strength/resistance exercise, flexibility, posture, coordination, and balance [5-7]. Table 1 below simplifies the predictors to assess high-risk patients during cardiac rehabilitation [8].

This literature review aimed to promote telemedicine specifically in $\mathrm{CR}$ through telerehabilitation programs among physicians and encourage each family member to actively support the continuum of rehabilitation programs at home to maintain and improve patients' quality of life. 
Table 1 Patients with high risk during cardiac rehabilitation [8]

\begin{tabular}{ll}
\hline Ischemic risk & Arrhythmia risk \\
\hline Postoperative angina & Acute infarction within 6 weeks \\
Left ventricular ejection fraction (LVEF) $<35 \%$ & Active ischemia by angina or exercise testing \\
NYHA grade III or IV congestive heart failure (CHF) & Significant left ventricular dysfunction (LVEF <30\%) \\
$\begin{array}{l}\text { Ventricular tachycardia or fibrillation in the postoperative period } \\
\text { The systolic blood pressure drop of } 10 \mathrm{mmHg} \text { or more with }\end{array}$ & History of sustained ventricular tachycardia \\
$\begin{array}{l}\text { exercise } \\
\text { Incapable of self-monitoring }\end{array}$ & History of sustained life-threatening supraventricular arrhythmia \\
Myocardial ischemia with exercise & History of sudden death \\
& Initial therapy of patients with automatic implantable cardioverter-defibrillator \\
& (AlCD) \\
\hline & Initial therapy of a patient with a rate-adaptive cardiac pacemaker
\end{tabular}

\section{Main text: phases of cardiac rehabilitation}

Cardiac rehabilitation is currently divided into three phases. The first phase is the acute phase, which starts from hospitalization following the heart attack up to the discharge, includes early mobilization programs. The second phase is the supervised rehabilitation phase initiated after complete healing and characterized by intense education and aerobic activities to achieve the desired exercise results. The third phase is the phase devoted to maintaining aerobic activities in phase II through a regular exercise program [8].

\section{Phase I (acute phase)}

The acute phase includes patient assessment, early mobilization, identification of CVD risk factors, and predischarge assessment. In this phase, outpatients are prepared to enter CR. Patients are given primary education on how to control risk factors and do self-care. The CR program is designed to make individuals mobilize from bed until they climb two stairs within 3-5 days. The types of activities commonly used in early mobilization are shown in Table $2[8,9]$.

Phase I's primary goal is that patients are capable of performing activities up to 4 metabolic equivalent tasks (METs). This value represents the estimated number of daily activities at home after discharge. Before discharge, patients perform an exercise test to determine their functional capacity, and then they are educated about which activities can be performed at home [8].

\section{Phase II}

The second phase begins as soon as patients are allowed to be discharged. The phase II or center-based cardiac rehabilitation (CBCR) phase is a program that provides resources and an environment, i.e., a supportive community for patients to complete their comprehensive rehabilitation program [10]. The CR program generally consists of 3 sessions per week for \pm 8 weeks. Patient risk stratification is necessary to determine the exercise prescription. The criteria of high-risk patients in $C R$ programs are listed in Table 3 [7-9].

In every risk category, direct supervision should be conducted. The supervision includes electrocardiogram (ECG) and hemodynamic examination. In this phase, a patient will undergo lung and neuromusculoskeletal examination, resting ECG, and risk profile to get a treadmill test [11].

\section{Phase III (maintenance phase)}

The third phase is the essential part of the program yet usually receives the least attention. The benefits gained from phase II (CBCR) will be subsided within a few weeks if they stop exercising [8]. Therefore, home-based cardiac rehabilitation (HBCR) may overcome this

Table 2 Types of activities commonly used in early cardiac rehabilitation [9]

\begin{tabular}{lll}
\hline Types of activities & Methods & METs \\
\hline Toileting & Bedpan & $1.5-2.5$ \\
& Commode & \\
& Urinal (in bed) & \\
& Urinal (standing) & \\
& In bed & $1.5-2.0$ \\
Bathing & In bathtub & \\
& Shower & \\
Walking & Flat surface & \\
& 2 m/h & $2.0-2.5$ \\
& 2.5 m/h & $2.5-2.9$ \\
& 3 m/h & $3.0-3.3$ \\
Upper body exercise & While standing & \\
& Arms movement & $2.5-3.0$ \\
Stairs climbing & Trunk movement & \\
& One flight = 12 steps & \\
& Down one flight & $3.0-4.0$ \\
& One to two flights & \\
\hline & & \\
& &
\end{tabular}

METs metabolic equivalent tasks 
Table 3 Characteristics of patients based on risk stratification $[7,9]$

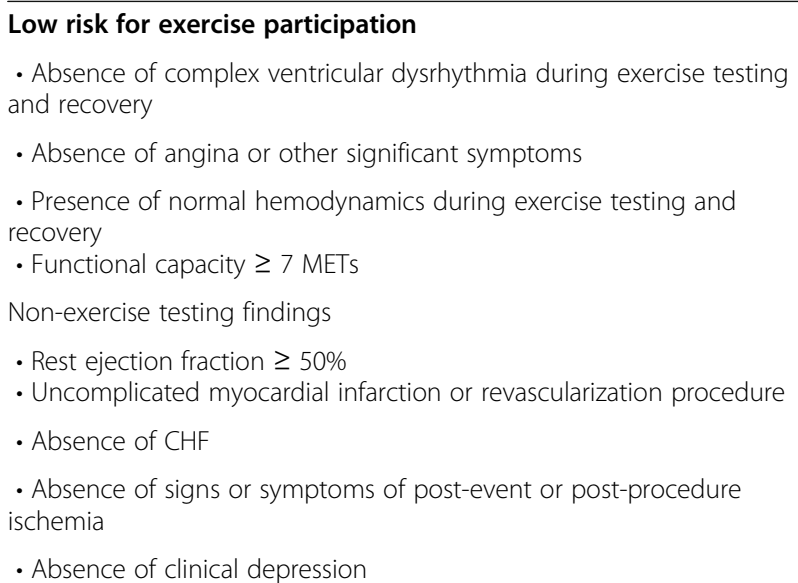

\section{High risk for exercise participation}

- Presence of complex ventricular arrhythmias during exercise testing or recovery

- Presence of angina or other significant symptoms

- High level of ischemia during exercise testing or recovery

- Presence of abnormal hemodynamics with exercise testing

Non-exercise testing findings

- Rest ejection fraction $<40 \%$

- History of cardiac arrest or sudden death

- Complex dysrhythmias at rest

- Complicated myocardial infarction or revascularization procedure

- Presence of CHF

- Presence of signs or symptoms of post-event or post-procedure ischemia

- Presence of clinical depression

METs metabolic equivalent tasks

CHF congestive heart failure

problem and be used as an adjunct or alternative to CBCR [10].

From the beginning of the CR program, sustaining an exercise program needs to be seriously emphasized. The exercises need to be integrated into patients' actual lifestyles to facilitate compliance in this phase. Moderate-intensity exercises should be performed at the heart rate target for at least $30 \mathrm{~min}$, three times/week, while low-intensity exercises should be performed five times/week [8].
If peak heart rate (HR) is unknown, we can use Borg scale, either the Borg Rating of Perceived Exertion (RPE) scale (primarily the Borg 6-20 RPE scale/BORG-RPE) or the Borg Category-Ratio-10 scale (BORG-CR10) to guide exercise intensity. For moderate intensity which scores 12-13 on BORG RPE (4-6 on BORG-CR10), is in somewhat hard criteria or having a target as $40-59 \%$ of HR reserve, while low intensity which scores below 12 on BORG RPE ( $<3$ on BORG-CR10) is in light criteria or having target as $<40 \%$ of $\mathrm{HR}$ reserve. Heart rate reserve is the difference between a person's measured heart rate (predicted maximum heart rate) and the resting heart rate [7]. ECG monitoring is not necessary during this phase [8].

\section{Benefits of cardiac rehabilitation}

Cardiac rehabilitation post-myocardial infarction (MI), post coronary artery bypass graft (CABG), and post percutaneous coronary intervention (PCI) are recommended (Class IA) by the American Heart Association (AHA) [12] and European Society of Cardiology (ESC) guidelines $[1,13,14]$. Cardiac rehabilitation positively impacts cardiorespiratory endurance, muscle mass and strength, mobility, physical activity, social interaction, cognitive performance, mood, and vitality of patients $[3$, 15]. This program is proven to improve self-care in the elderly, avoid unnecessary hospitalizations, and improve patients' quality of life [15]. Secondary prevention, including $\mathrm{CR}$, is crucial to improve the long-term prognosis of patients with MI and increase their functional capacity [4]. Cardiac rehabilitation is also considered to improve cardiorespiratory fitness and heart rate recovery, which are indicators of autonomic function in coronary artery disease (CAD) patients with a previous $\mathrm{MI}$ history. Cardiac rehabilitation may reduce the length of stay, depression rate, the incidence of recurrent acute coronary syndrome, disability, stroke, and on the other hand, improve medication adherence [15-17].

The rehabilitation program benefits are gained from the direct physiological effects of physical exercises and the indirect effects of risk factors control, lifestyle modification, and mood. Several studies had shown that patients who underwent $\mathrm{CR}$ programs following primary PCI had a lower mortality rate $[13,16]$.

\section{Types of cardiac rehabilitation}

The CR programs are available in two forms: centerbased cardiac rehabilitation (CBCR) and home-based cardiac rehabilitation (HBCR). The CBCR exercises are conducted in hospitals or specialized institutions, which is safer for cardiac disease patients because professionals supervise them. However, the CBCR program cost is quite expensive since it is a long-term program and may not be convenient for patients living in rural areas [3]. 
Therefore, HBCR is recommended for patients who experience limitations to CBCR. Patients who dislike group activities but are disciplined and have leisure time are the ideal candidates for HBCR [10]. In the HBCR program, patients can still participate and perform exercises independently at home or any local fitness center [3].

The CBCR program had a very high dropout rate (up to $24-50 \%)$, suggesting that the long-term exercises of CBCR were not continuously performed by most of the patients, whereas the progress been made after completing the program will not be maintained if the exercises are stopped [3, 18]. Moreover, lower exercise compliance caused increased body weight, and lipid levels were reported as patients stopped the CBCR program. Therefore, these exercises are only recommended at the beginning of the rehabilitation program, and then patients are recommended to continue on the HBCR program [3].

Both CBCR and HBCR programs effectively improved clinical outcomes and health-related quality of life (HRQoL) in patients with CAD, MI, or low-risk HF. The efficacy of HBCR was comparable to CBCR in terms of increased aerobic capacity, level of physical activity, exercise compliance, controlled BP, and cholesterol level. The HBCR effectively reduced cardiac mortality in patients with CAD, ranging between 27 and $31 \%[5,18$, 19].

Patients frequently do not participate in CR due to their low perception of the program's importance and necessity. The less optimal participation may lead to less optimal results in CR $[3,16]$.

The primary strategy for improving adherence in rehabilitation works through a strong doctor-patient relationship and good communication skills, ensuring patient understanding of the impacts of non-adherence. Physician support indeed influences patient participation in CR programs. Patient characteristics may be the significant predictors when referring patients to join $C R$ programs $[2,10]$.

Of all patients who were referred to CR, only $30-34 \%$ participated [10]. The low rate of patient participation is influenced by several factors, including lack of physician referral or low level of physician support, low socioeconomic status, lack of education, racial/ethnic minority status, barriers in transportation, current routine activities at home, older age, female gender, lack of friends, and the presence of depression. The participation rate in $\mathrm{CR}$ is lower in women than men because women tend to do household chores, have low interest, and comorbidities such as knee and back pain $[3,10]$.

The HBCR program has proven to be safe, costeffective, and acceptable to communities. In Indonesia, patients considered safe to do the HBCR program are commonly categorized as low-risk patients, do not require ECG monitoring, and can be monitored by daily reports via logbook or diary. Compared to CBCR, most patients can complete the HBCR program. Selfmonitoring and self-management in HBCR will make a better transition from active interventions to lifelong independence of patients. The HBCR is considered safe because there are no reports or evidence of increased hospitalization or death risk. These findings support the HBCR program applied to HF patients as an alternative to conventional hospital-based rehabilitation $[10,18,20]$.

The HBCR program includes the core components of the CBCR program, which is delivered by a health care professional but may be delivered through telephone calls or cellular technologies. This program may expand the modalities of patient education, counseling, and monitoring because this service, which has been implemented in the USA, can be accessed $24 \mathrm{~h}$ a day and 7 days a week; therefore, making it easier to be accessed compared to contact professionals in the CBCR [18].

The use of information and communication technology may be worth adjunctive to CR. It is known as telemedicine. Telemedicine is considered suitable, safe, and effective in increasing exercise capacity, controlling shortness of breath, maintaining physical activity, reducing disability, and improving quality of life in elderly patients with chronic obstructive pulmonary disease (COPD), CHF, and ischemic heart disease [1, 17, 18]. The virtual CR program is a part of HBCR innovations to facilitate or maximize care quality and effectiveness. This innovation works through communication via telephone and video conferencing, e-mails, letters, text messaging, smartphone applications, and online platforms. Telemedicine applied in CR, called telerehabilitation, may become a solution for a more optimal HBCR implementation. This program is targeted for low-tomoderate risk patients, whereas high-risk patients need to continue their rehabilitation through the CBCR program [17, 18, 21-23].

The transition from conventional rehabilitation into virtual CR needs three main steps. In the first 6 weeks, $\mathrm{CR}$ should be done immediately by using available resources. Then in the next 6 months, the delivery should be standardized and optimized. The next step is the delivery should be developed and more innovative. The practical tips for establishing virtual $\mathrm{CR}$ can be seen in Fig. 1.

Access to health care professionals through a portal web of affiliated institutions may reduce costs and promote adherence to sustained healthy lifestyle changes. Interventions using mobile health had been proven effective for improving exercise outcomes in patients with cardiovascular diseases, controlling body weight and body mass index, and improving adherence to medical therapies. The HBCR using mobile health increased 


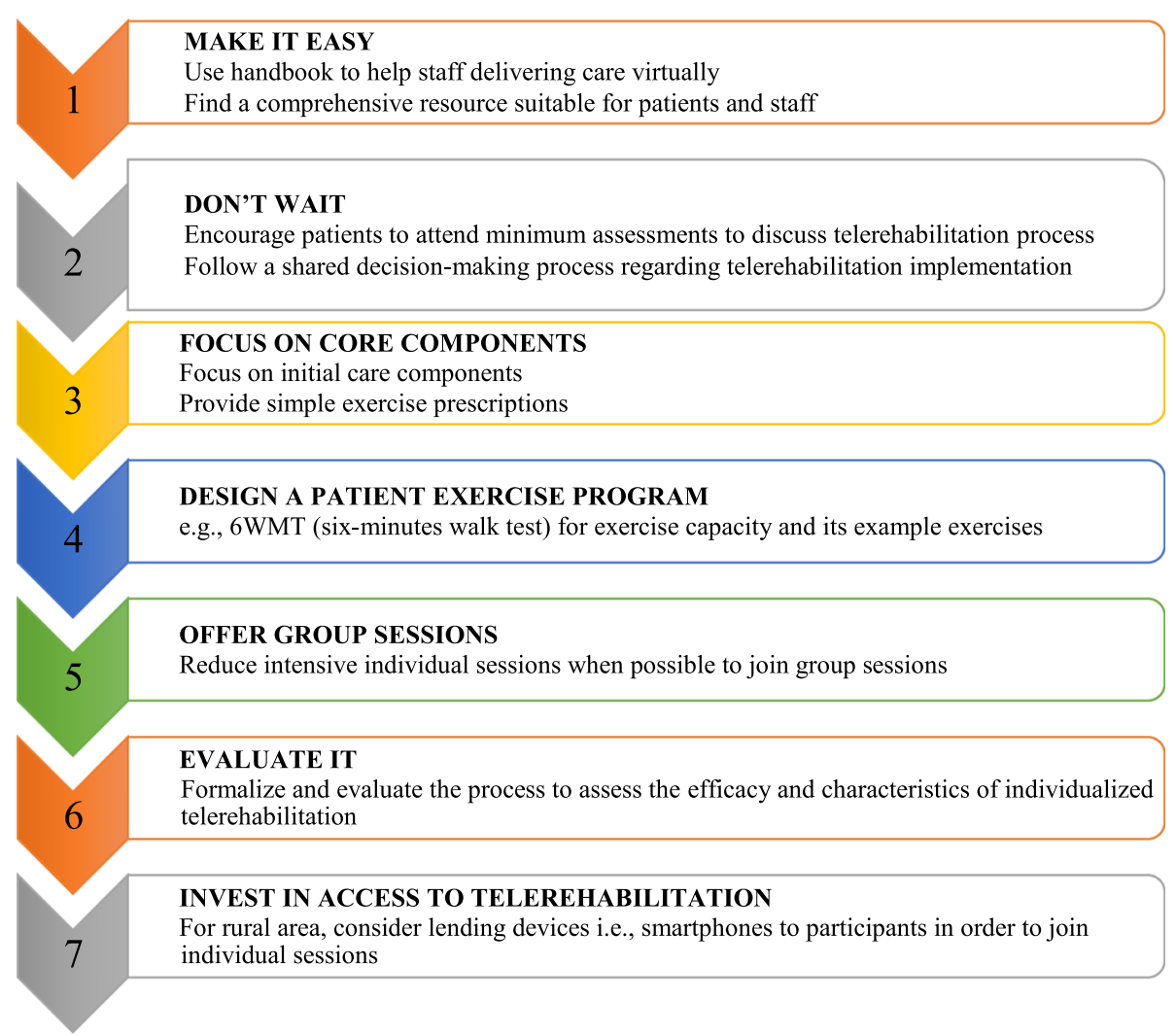

Fig. 1 Practical tips for establishing a virtual cardiac rehabilitation program [22]

participation rates and compliance of participants. Text messaging and the internet are useful for increasing levels of physical activity. A short text message reminding exercises can be applied to increase the number of sessions attended. Figure 2 describes some devices and parameters used in telerehabilitation and monitors the patients $[18,23]$.

Telerehabilitation appears to be at least as effective as conventional rehabilitation. This delivery model has been successfully trialed in patients with various cardiopulmonary diseases. In a study where HBCR was delivered via computer/tablet, all participants with COPD remained actively participating in the program after 1 year [24].

\section{Cardiac rehabilitation in pandemic situation}

The coronavirus disease-2019 (COVID-19) pandemic has a significant impact on health care globally, including acute and chronic cardiac care. The consequence is the global physical activity levels that dropped dramatically due to policies and the warning which encourage people to live and work at home and keep up physical distancing. Unfortunately, these recommendations do not emphasize the importance of maintaining a healthy lifestyle while staying at home $[25,26]$.
Recent guidelines from the Centers for Disease Control and Prevention (CDC) recommend all high-risk individuals, including those with cardiovascular risk factors, stay at home to limit the potential exposure to COVID-19. Almost all hospital-based rehabilitation programs are closed, and many elective and outpatient health care activities are canceled or suspended during the COVID-19 pandemic. A consensus guideline from experts recommends limiting direct contact between rehabilitation therapists and patients due to the high transmission rates of COVID-19. The guideline suggests telemedicine as an option for screening and, if possible, for providing treatment to patients. Telemedicine may be considered as electronic personal protective equipment (PPE) by reducing the risk of exposure and contamination for both patients and practitioners [27].

Telemedicine in Indonesia has already been applied and regulated by Permenkes No. 20 Tahun 2019. On the other side, the COVID-19 pandemic has led to a large-scale shift toward telemedicine (or virtual health services) in the general population to deliver health care services while still implementing COVID-19 health protocols. It applies to rehabilitation programs that demand sustainability; therefore, new interventions are 


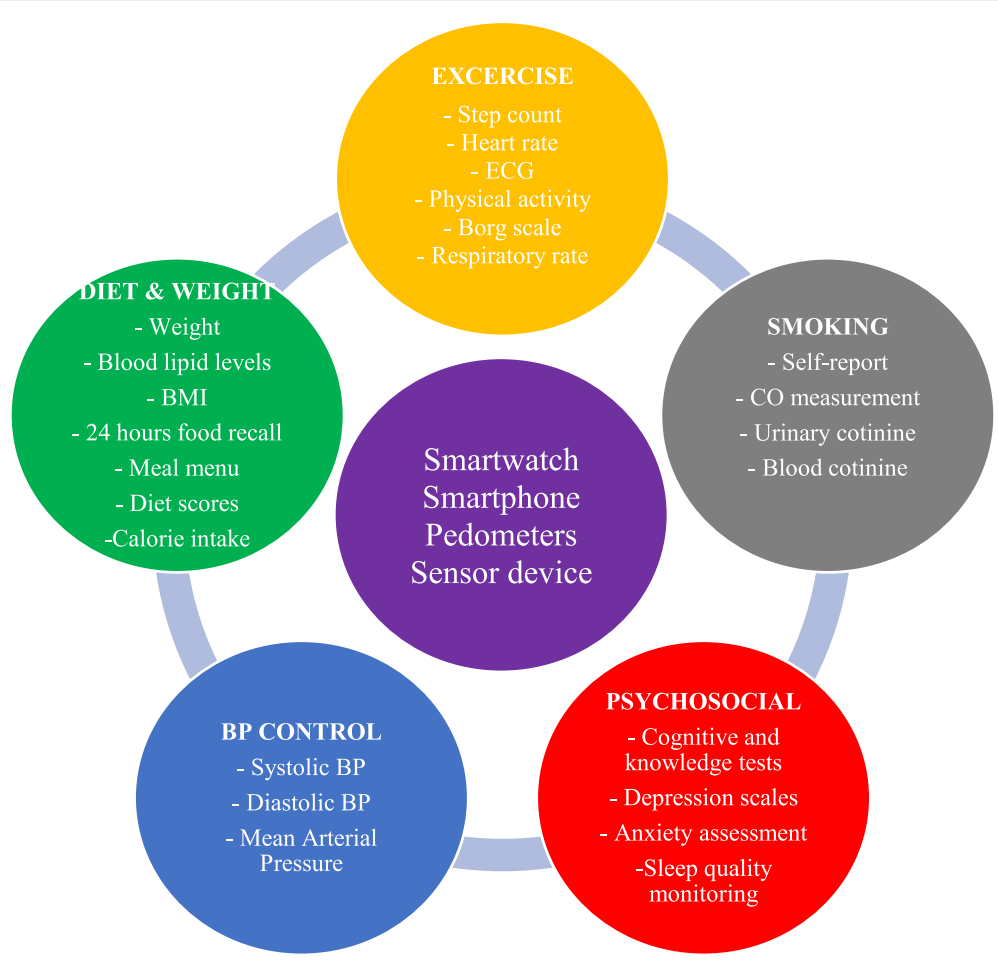

Fig. 2 Monitoring devices and parameters of telerehabilitation [23]. BP, blood pressure; CO, carbon monoxide; BMl, body mass index; ECG, electrocardiogram

required to provide rehabilitation services, primarily through telerehabilitation [28].

A study suggests that in the shortened CR program, exercises are focused on the main core components (i.e., education, medical therapy, lifestyle risk management, and psychosocial support) with an individualized approach based on residual cardiac risks, psychological symptoms, and lifestyle assessment. Face-to-face sessions can be replaced with remote assessment and monitoring/guiding through telerehabilitation. Patient assessment and risk stratification are generated by exercise tests whenever possible. Otherwise, other tools can assess cardiovascular risk and physical fitness to provide personalized exercise advice and guide telerehabilitation. For CVD patients who are positive for COVID-19, the exercise program may be postponed if COVID-19's signs and symptoms are still present. Evaluate exercise resumption is on an individual basis. In general, patients with mild-to-moderate symptoms can gradually restart the exercise program after no fever in a week and no symptoms in $48 \mathrm{~h}$. Whenever possible, all components of the CR program are not suspended but provided remotely [26].

Fifty-two percent of rehabilitation centers in Belgium already provided cardiac rehabilitation programs by implementing telerehabilitation [29]. The remote CR application involved physicians, nurses, dieticians, physiotherapists, and psychologists $[29,30]$. All of the CR components were conducted, such as exercise training, dietary advice, smoking cessation guidance, cardiovascular education, psychosocial support, medication adherence, and weight management [13, 29]. The frequency of supervision was diverse, between once a month into several times a week [14, 29].

While at least 35 centers reported delivering CR programs using telerehabilitation in Canada. The remote program reported were using telerehabilitation to deliver exercise program (32\% of the programs) and education program (43.5\%). Exercise was delivered using telephone, e-mail, mailing forms/resources by post, and web-based platform resources. These methods were significantly increased [6].

The other differences in conducting the CR program during COVID-19 were that the eligibility criteria have shifted to lower risk and less complex patients. The services also are limited, such as initial assessments, consultation, stress management, and group-based education for nutrition [6].

Things that need to be considered in carrying out telerehabilitation are the right staff, the ability to use technology, and other methods of implementing telerehabilitation if the patient does not have access to technology. Developing strategies to admit high-risk/vulnerable populations into the $\mathrm{CR}$ program should be concerned 
[6]. The criteria of a patient in a telerehabilitation program will be challenging during the pandemic. Telerehabilitation implementation needs to prepare technology that ensures communication between teams because CR requires multidisciplinary collaboration [30].

During lockdown, telemedicine can provide many benefits, so it can be a useful intervention to avoid stress and boost the immune system by applying the exercises recommended by CR. It has a real impact on elderly patients with CVD [31].

Patients can still exercise without any equipment during pandemics, such as gymnastic movements of muscular strengthening (squat, sit-to-stand, push-ups against a wall, 1-L water bottles for weights to exercise the upper body, etc.), balance or stretching training, and online relaxation sessions. These exercises can be easily described and explained to the patient by using videos. Moreover, it can be illustrated in a physical activity notebook [32].

An important note that the particular HBCR exercise prescription (more than $30 \mathrm{~min}$ of moderate-intensity exercise and 3-5 sessions per week) should have to be modified for individuals who used to walk/run outside. Other forms of physical activity, such as chair-based exercises, calisthenics, resistance, and balance exercises, should be explored. The yoga trends in CR could be a prospect to be used among patients with CVD [33].

By using a logbook, patients can follow the practice of regular training during quarantine. Fifteen minutes per day, every day may be enough to fight against muscle deconditioning and avoid the harmful impacts of strict confinement. However, a precise individualized prescription for each patient is still needed to assure their safety. To increase adherence, coaching by phone seems to be potential and reduces harmful impacts on psychological and physical health, especially in the elderly population [32].

To ensuring patient safety, trackers may be used to quantify physical activity. The equipment is expected to record and send variables (energy expenditure, body mass, glycemia, BP, HR, ECG, etc.) measured via sensors to a web platform accessible to the physician, nurses, and the centers. Simultaneously, real-time monitoring, such as ECG and BP measurement during exercise, is still a challenge to be solved [32].

\section{Conclusions}

The cardiac rehabilitation (CR) program is a sustainable and multidisciplinary intervention where patients are encouraged to continuously implement a healthy lifestyle and regular exercise after starting the program. This program should include physical training, risk factor modification, education, stress management, and psychological support. The CR programs are available in two forms: center-based cardiac rehabilitation (CBCR) and home-based cardiac rehabilitation (HBCR).

The progress made after completing the CBCR program is often not well-maintained for many reasons; therefore, HBCR is highly recommended since patients' training and participation can be done independently at home. Moreover, long-term adherence to medication and a healthy lifestyle is crucial since they are associated with a lower risk of death and recurrence.

Using multiple technology modalities may be superior to using a single modality. Implementing information and communications technology in medicine, known as telemedicine, maybe a worth alternative to CR. There were already some countries that have been applied telerehabilitation. Moreover, it is highly recommended in the current COVID-19 pandemic, where patients are advised to perform remote consultations unless in urgent conditions. Thus, physicians play an essential role in motivating patients and encouraging their family members to commit to a sustainable CR program with telerehabilitation to facilitate its implementation. It is essential for rehabilitation physicians and family doctors to regularly monitor patients in primary health care facilities.

\begin{abstract}
Abbreviations
AHA: American Heart Association; AICD: Automatic implantable cardioverterdefibrillator; BMI: Body mass index; BP: Blood pressure; CABG: Coronary artery bypass graft; CAD: Coronary artery disease; CBCR: Center-based cardiac rehabilitation; CDC: Centers for Disease Control and Prevention;

CHF: Congestive heart failure; CO: Carbon monoxide; COPD: Chronic obstructive pulmonary disease; COVID-19: Coronavirus disease-2019;

CR: Cardiac rehabilitation; CVD: Cardiovascular disease;

ECG: Electrocardiogram; ESC: European Society of Cardiology; HBCR: Homebased cardiac rehabilitation; HF: Heart failure; HR: Heart rate; HRQoL: Healthrelated quality of life; LVEF; Left ventricular ejection fraction; NYHA: New York Heart Association; METs: Metabolic equivalent tasks; MI: Myocardial infarction; PCI: Percutaneous coronary intervention; PPE: Personal protective equipment; RPE: Rating of perceived exertion
\end{abstract}

Acknowledgements

Not applicable.

Authors' contributions

LC collected articles and references. DM and LC discussed and organized the content in manuscript. All authors read and approved the final manuscript.

Funding

None.

Availability of data and materials

Not applicable.

\section{Declarations}

Ethics approval and consent to participate

Not applicable.

Consent for publication

Not applicable.

Competing interests

The authors declare that they have no competing interests. 


\section{Author details}

'Department of Physical Medicine and Rehabilitation, Faculty of Medicine, Universitas Padjadjaran, Bandung, Indonesia. ${ }^{2}$ Faculty of Medicine, Maranatha Christian University, Bandung, Indonesia.

\section{Received: 15 December 2020 Accepted: 16 March 2021}

\section{Published online: 29 March 2021}

\section{References}

1. Doimo S, Fabris E, Piepoli M, Barbati G, Antonini-Canterin F, Bernardi G, Maras P, Sinagra G (2019) Impact of ambulatory cardiac rehabilitation on cardiovascular outcomes: a long-term follow-up study. Eur Heart J 40(8): 678-685. https://doi.org/10.1093/eurheartj/ehy417

2. Hald K, Larsen FB, Nielsen KM, Meillier LK, Johansen MB, Larsen ML, Christensen B, Nielsen CV (2019) Medication adherence, biological and lifestyle risk factors in patients with myocardial infarction: a ten-year followup on socially differentiated cardiac rehabilitation. Scand J Prim Health Care 37(2):182-190. https://doi.org/10.1080/02813432.2019.1608046

3. Kim YH, So WY (2019) Gender differences in home-based cardiac rehabilitation of post-percutaneous coronary intervention patients. Aging Clin Exp Res 31(2):249-255. https://doi.org/10.1007/s40520-018-0951-8

4. Hald K, Nielsen KM, Nielsen CV, Meillier LK, Larsen FB, Christensen B, Larsen ML (2018) Expanded cardiac rehabilitation in socially vulnerable patients with myocardial infarction: a 10-year follow-up study focusing on mortality and non-fatal events. BMJ Open 8(1):e019307. https://doi.org/10.1136/ bmjopen-2017-019307

5. Noites A, Freitas CP, Pinto J, Melo C, Vieira Á, Albuquerque A, Teixeira M, Ribeiro F, Bastos JM (2017) Effects of a phase IV home-based cardiac rehabilitation program on cardiorespiratory fitness and physical activity. Heart Lung Circ 26(5):455-462. https://doi.org/10.1016/j.hlc.2016.08.004

6. Marzolini S, Ghisi G, Hébert AA, Ahden S, Oh P (2021) Cardiac rehabilitation in Canada during COVID-19. CJC Open 3(2):152-158. https://doi.org/10.101 6/j.cjco.2020.09.021

7. Riebe D, Ehrman JK, Liguori G, Magal M (2018) ASCM's guidelines for exercise testing and prescription, 10th edn. Wolters Kluwer Health, Philadelphia, pp 184-188

8. Bartels M (2010) Cardiac rehabilitation. In: Frontera WR, DeLisa JA, Gans BM, Walsh NE, Robinson LR (eds) DeLisa's Physical Medicine \& Rehabilitation Principles and Practice, vol 1, 5th edn. Lippincott Williams \& Wilkins, Philadelphia, pp 1075-1097

9. American Association of Cardiovascular and Pulmonary Rehabilitation (2013) Guidelines for cardiac rehabilitation and secondary prevention programs, 5th edn. Human Kinetics, Champaign

10. Dunn SL, Dunn LM, Buursma MP, Clark JA, Berg LV, DeVon HA et al (2017) Home- and hospital-based cardiac rehabilitation exercise: the important role of physician recommendation. West J Nurs Res 39(2):214-233. https://doi. org/10.1177/0193945916668326

11. Tedjasukmana D (2017) Return to work in patients with acute coronary syndrome. Indonesian J Phys Med Rehabil 6(02):23. https://doi.org/10.36803/ ijpmr.v6i02.159

12. Leon AS, Franklin BA, Costa F, Balady GJ, Berra KA, Stewart KJ, Thompson PD, Williams MA, Lauer MS (2005) Cardiac rehabilitation and secondary prevention of coronary heart disease. Circulation. 111(3):369-376. https:// doi.org/10.1161/01.CIR.0000151788.08740.5C

13. Ibanez B, James S, Agewall S, Antunes MJ, Bucciarelli-Ducci C, Bueno H, Caforio ALP, Crea F, Goudevenos JA, Halvorsen S, Hindricks G, Kastrati A, Lenzen MJ, Prescott E, Roffi M, Valgimigli M, Varenhorst C, Vranckx P, Widimský P, ESC Scientific Document Group, Collet JP, Kristensen SD, Aboyans V, Baumbach A, Bugiardini R, Coman IM, Delgado V, Fitzsimons D, Gaemperli O, Gershlick AH, Gielen S, Harjola VP, Katus HA, Knuuti J, Kolh P, Leclercq C, Lip GYH, Morais J, Neskovic AN, Neumann FJ, Niessner A, Piepoli MF, Richter DJ, Shlyakhto E, Simpson IA, Steg PG, Terkelsen CJ, Thygesen K, Windecker S, Zamorano JL, Zeymer U, Windecker S, Aboyans V, Agewall S, Barbato E, Bueno H, Coca A, Collet JP, Coman IM, Dean V, Delgado V, Fitzsimons D, Gaemperli O, Hindricks G, lung B, Jüni P, Katus HA, Knuuti J, Lancellotti P, Leclercq C, McDonagh T, Piepoli MF, Ponikowski P, Richter DJ, Roffi M, Shlyakhto E, Simpson IA, Zamorano JL, Chettibi M, Hayrapetyan HG, Metzler B, Ibrahimov F, Sujayeva V, Beauloye C, Dizdarevic-Hudic L, Karamfiloff K, Skoric B, Antoniades L, Tousek P, Terkelsen PCJ, Shaheen SM, Marandi T, Niemelä M, Kedev S, Gilard M, Aladashvili A, Elsaesser A, Kanakakis IG, Merkely B, Gudnason T, lakobishvili Z, Bolognese L,
Berkinbayev S, Bajraktari G, Beishenkulov M, Zake I, Lamin HB, Gustiene O, Pereira B, Xuereb RG, Ztot S, Juliebø V, Legutko J, Timóteo AT, Tatu-Chitoiu G, Yakovlev A, Bertelli L, Nedeljkovic M, Studenčan M, Bunc M, García de Castro AM, Petursson P, Jeger R, Mourali MS, Yildirir A, Parkhomenko A, Gale CP (2018) 2017 ESC Guidelines for the management of acute myocardial infarction in patients presenting with ST-segment elevation. Eur Heart J 39(2):119-177. https://doi.org/10.1093/eurheartj/eh×393

14. Thomas RJ, Beatty AL, Beckie TM, Brewer LC, Brown TM, Forman DE et al (2019) Home-based cardiac rehabilitation: a scientific statement from the American Association of Cardiovascular and Pulmonary Rehabilitation, the American Heart Association, and the American College of Cardiology. J Am Coll Cardiol 74(1):133-153. https://doi.org/10.1016/j.jacc.2019.03.008

15. Afilalo J (2019) Evaluating and treating frailty in cardiac rehabilitation. Clin Geriatr Med 35(4):445-457

16. Sunamura M, Ter Hoeve $N$, van den Berg-Emons RJG, Boersma E, Geleijnse ML, van Domburg RT (2020) Patients who do not complete cardiac rehabilitation have an increased risk of cardiovascular events during longterm follow-up. Neth Hear J 28(9):460-466. https://doi.org/10.1007/s12471020-01413-1

17. Vieira Á, Melo C, Machado J, Gabriel J (2018) Virtual reality exercise on a home-based phase III cardiac rehabilitation program, effect on executive function, quality of life and depression, anxiety and stress: a randomized controlled trial. Disab Rehabil Assist Technol 13(2):112-123. https://doi.org/1 0.1080/17483107.2017.1297858

18. Beckie TM (2019) Utility of home-based cardiac rehabilitation for older adults. Clin Geriatr Med 35(4):499-516. https://doi.org/10.1016/j.cger.2019.07.003

19. Bravo-Escobar R, González-Represas A, Gómez-González AM, Montiel-Trujillo A, Aguilar-Jimenez R, Carrasco-Ruíz R, Salinas-Sánchez P (2017) Effectiveness and safety of a home-based cardiac rehabilitation programme of mixed surveillance in patients with ischemic heart disease at moderate cardiovascular risk: a randomised, controlled clinical trial. BMC Cardiovasc Disord 17(1):66. https://doi.org/10.1186/s12872-017-0499-0

20. Zwisler AD, Norton RJ, Dean SG, Dalal H, Tang LH, Wingham J, Taylor RS (2016) Home-based cardiac rehabilitation for people with heart failure: a systematic review and meta-analysis. Int J Cardiol 221:963-969. https://doi. org/10.1016/j.ijcard.2016.06.207

21. Bernocchi P, Vitacca M, La Rovere MT, Volterrani M, Galli T, Baratti D et al (2018) Home-based telerehabilitation in older patients with chronic obstructive pulmonary disease and heart failure: a randomised controlled trial. Age Ageing 47(1):82-88. https://doi.org/10.1093/ageing/afx146

22. Moulson N, Bewick D, Selway T, Harris J, Suskin N, Oh P, Coutinho T, Singh G, Chow CM, Clarke B, Cowan S, Fordyce CB, Fournier A, Gin K, Gupta A, Hardiman S, Jackson S, Lamarche Y, Lau B, Légaré JF, Leong-Poi H, Mansour S, Marelli A, Quraishi AR, Roifman I, Ruel M, Sapp J, Small G, Turgeon R, Wood DA, Zieroth S, Virani S, Krahn AD (2020) Cardiac rehabilitation during the COVID-19 era: guidance on implementing virtual care. Can J Cardiol 36(8):1317-1321. https://doi.org/10.1016/j.cjca.2020.06.006

23. Scherrenberg M, Wilhelm M, Hansen D, Völler H, Cornelissen V, Frederix I, Kemps H, Dendale P (2020) The future is now: a call for action for cardiac telerehabilitation in the COVID-19 pandemic from the secondary prevention and rehabilitation section of the European Association of Preventive Cardiology. Eur J Prev Cardiol. https://doi.org/10.1177/204748732093967

24. Hwang R, Bruning J, Morris NR, Mandrusiak A, Russell T (2017) Home-based telerehabilitation is not inferior to a centre-based program in patients with chronic heart failure: a randomised trial. J Physiother 63(2):101-107. https:// doi.org/10.1016/j.jphys.2017.02.017

25. Khera A, Baum SJ, Gluckman TJ, Gulati M, Martin SS, Michos ED, Navar AM, Taub PR, Toth PP, Virani SS, Wong ND, Shapiro MD (2020) Continuity of care and outpatient management for patients with and at high risk for cardiovascular disease during the COVID-19 pandemic: a scientific statement from the American Society for Preventive Cardiology. Am J Prev Cardiol 1:100009. https://doi.org/10.1016/j.ajpc.2020.100009

26. Kemps HMC, Brouwers RWM, Cramer MJ, Jorstad HT, De Kluiver EP, Kraaijenhagen RA et al (2020) Recommendations on how to provide cardiac rehabilitation services during the COVID-19 pandemic. Neth Hear J 28(7-8): 387-390. https://doi.org/10.1007/s12471-020-01474-2

27. Rosen K, Patel M, Lawrence C, Mooney B (2020) Delivering telerehabilitation to COVID-19 inpatients: a retrospective chart review suggests it is a viable option. HSS J. https://doi.org/10.1007/s11420-020-09774-4

28. Yu JC, Mcintyre M, Dow H, Robinson L, Winston P (2020) Changes to rehabilitation service delivery and the associated physician perspectives 
during the COVID-19 pandemic. Am J Phys Med Rehabil 99(9):775-782. https://doi.org/10.1097/PHM.0000000000001516

29. Scherrenberg M, Frederix I, De Sutter J, Dendale P (2020) Use of cardiac telerehabilitation during COVID-19 pandemic in Belgium. Acta Cardiol 30:14. https://doi.org/10.1080/00015385.2020.1786625

30. Tersalvi G, Winterton D, Cioffi GM, Ghidini S, Roberto M, Biasco L, Pedrazzini G, Dauw J, Ameri P, Vicenzi M (2020) Telemedicine in heart failure during COVID-19: a step into the future. Front Cardiovasc Med 7. https://doi.org/1 0.3389/fcrm.2020.612818

31. Ribeiro F, Santos M (2020) Exercise-based cardiac rehabilitation in COVID-19 times: one small step for health care systems, one giant leap for patients. Revista espanola de cardiologia (English ed) 73(11):969-970. https://doi. org/10.1016/j.rec.2020.07.002

32. Besnier F, Gayda M, Nigam A, Juneau M, Bherer L (2020) Cardiac rehabilitation during quarantine in COVID-19 pandemic: challenges for center-based programs. Arch Phys Med Rehabil 101(10):1835-1838. https:// doi.org/10.1016/.j.apmr.2020.06.004

33. Babu AS, Arena R, Ozemek C, Lavie CJ (2020) COVID-19: a time for alternate models in cardiac rehabilitation to take centre stage. Can J Cardiol 36(6): 792-794. https://doi.org/10.1016/j.cjca.2020.04.023

\section{Publisher's Note}

Springer Nature remains neutral with regard to jurisdictional claims in published maps and institutional affiliations.

\section{Submit your manuscript to a SpringerOpen ${ }^{\circ}$ journal and benefit from:}

- Convenient online submission

- Rigorous peer review

- Open access: articles freely available online

- High visibility within the field

- Retaining the copyright to your article

Submit your next manuscript at $\boldsymbol{\nabla}$ springeropen.com 